\title{
Pollen morphology of selected species of the genera Chrysodracon and Dracaena (Asparagaceae, subfamily Nolinoideae) and its systematic implications
}

\author{
Małgorzata Klimko ${ }^{1} \cdot$ Renata Nowińska ${ }^{1}$ • Joanna Jura-Morawiec ${ }^{2} \cdot$ Justyna Wiland-Szymańska $^{3} \cdot$ Paul Wilkin $^{4}$
}

Received: 8 July 2017 / Accepted: 8 December 2017 / Published online: 19 January 2018

(c) The Author(s) 2018. This article is an open access publication

\begin{abstract}
Pollen grains of 3 species from the genus Chrysodracon and 20 species from the genus Dracaena were examined by light, scanning electron and fluorescence microscopy. The basic shape of the pollen grains is subprolate and prolate, but prolatespheroidal pollen grains may also be found. Pollen of Chrysodracon and Dracaeana is dispersed as monads, rarely as dyads. In terms of size, the pollen grains studied were classified as medium-sized and large. There are two different types of apertures: monosulcate and monoulcerate in Dracaena and monoulcerate in Chrysodracon. The surface of the non-apertural areas is psilate-perforate, irregularly folded, microreticulate and fossulate. Ornamentation of the apertural region is microreticulate, microreticulate-baculate, baculate, psilate-perforate, psilate-perforate-verrucate, granulate and irregularly folded. Irregular perforations are present, and the wall structure is tectate-columellate. Our results suggest that some species of Chrysodracon and Dracaena may be separated based on their pollen grain micromorphology on the distal region.
\end{abstract}

Keywords Chrysodracon $\cdot$ Dracaena $\cdot$ Micromorphology $\cdot$ Monocot $\cdot$ Palynology $\cdot$ Taxonomy

\section{Introduction}

The systematics of the dracenoid clade of Asparagaceae (APG III 2009) is so far not completely resolved. The genus Dracaena Vand. and its two other closely allied genera Pleomele Salisb. and Sansevieria Thunb. are recognized differently by various authors.

Observed similarity in floral morphology induced some authors to include the genus Sansevieria into Dracaena (e.g., Bos 1984, 1998). Recent molecular phylogenetic studies

Handling Editor: Luke Mander.

Renata Nowińska

renata.nowinska@up.poznan.pl

1 Department of Botany, Poznań University of Life Sciences, Wojska Polskiego 71 C, 60-625 Poznań, Poland

2 Polish Academy of Sciences Botanical Garden, Centre for Biological Diversity Conservation in Powsin, Prawdziwka 2, 02-973 Warsaw, Poland

3 Department of Plant Taxonomy, Adam Mickiewicz University, Umultowska 89, 61-614 Poznań, Poland

4 Royal Botanic Gardens, Kew, Surrey, Richmond TW9 3AB, UK show that Sansevieria is nested within Dracaena sensu lato (Lu and Morden 2014). However, other researchers have treated Sansevieria as a separate taxon at genetic rank (Brown 1914; Jankalski 2003; Wiland-Szymańska and Klimko 2005; Mansfeld 2015) due to differences from Dracaena in morphological, palynological and carpological characters.

The genus Dracaena was founded in 1768 by Vandelli upon Dracaena draco L. (Brown 1914). Due to dissimilarities in the structure of flowers, the species described in this genus were allocated by Brown into two genera: Dracaena sensu stricto with divided tepals and filaments of stamens centrally thickened and Pleomele Salisb., characterized by a long perianth tube and filiform stamina filaments (Brown 1914). This division was not generally agreed upon, and species with the Pleomele characters were generally referred to as Dracaena (e.g., Bos 1998). The two genera were combined by Jankalski (2008), who recognized Dracaena as a genus with two subgenera: subg. Dracaena and subg. Pleomele. The available molecular data support unification of these taxa into one genus Dracaena (Lu and Morden 2014). These genetic concepts are those currently accepted within the dracenoids, with Dracaena containing both species of the dragon tree group with free tepals and the mesophytic group with long-tubed flowers. 

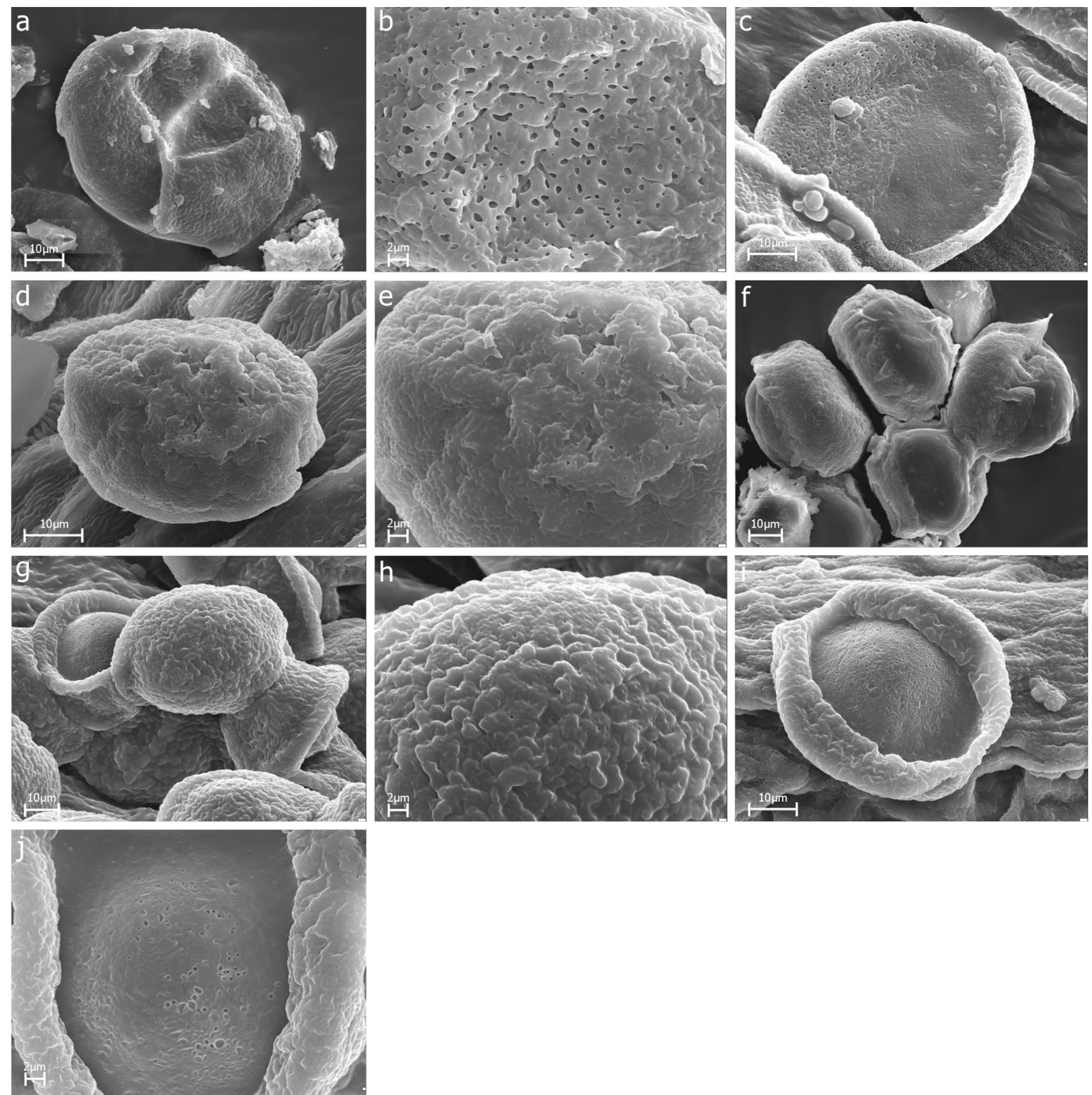

Fig. 1 SEM micrographs of pollen grains of Chrysodracon species studied. a-c Chrysodracon aurea. a In proximal view. b Exine surface, enlargement of a. c In distal view. d-f Chrysodracon fernaldii. d In proximal view. e Exine surface, enlargement of $\mathbf{d}$. $\mathbf{f}$ In lateral and

The third group recognized by Jankalski (2008) was Dracaena subg. Chrysodracon Jankal. composed of the species included before into Pleomele and endemic to the Hawaii Islands. As they are characterized by unique floral characters and form a distinct sister clade to other species of dracenoids, they were delineated as a separate distal view. g- j Chrysodracon forbesii. $\mathbf{g}$ In proximal and distal view. h Exine surface, enlargement of $\mathbf{g}$. i In distal view. j Exine surface, enlargement of $\mathbf{i}$

genus Chrysodracon P.L.Lu \& Morden by Lu and Morden (2014). Concluding, in this paper, we recognize three genera within the dracenoid clade: Dracaena, Sansevieria and Chrysodracon.

Pollen characters, e.g., aperture type, variation in exine ornamentation and wall structure, have frequently been 
Table 1 Quantitative features of pollen grains in Chrysodracon and Dracaena species with the results of one-way ANOVAs

\begin{tabular}{|c|c|c|c|c|c|c|c|c|c|}
\hline \multirow[t]{2}{*}{ Features species } & \multicolumn{3}{|c|}{ Length of long axis (LA) } & \multicolumn{3}{|c|}{ Length of short axis (SA) } & \multicolumn{3}{|c|}{ LA/SA ratio } \\
\hline & Min & Max & Mean \pm SD & Min & Max & Mean \pm SD & Min & Max & Mean \pm SD \\
\hline Chrysodracon aurea & 45.8 & 74.1 & $60.2 \pm 7.2$ & 21.2 & 56.5 & $40.8 \pm 8.3$ & 1.1 & 2.6 & $1.53 \pm 0.35$ \\
\hline C. fernaldii & 45.8 & 63.5 & $51.8 \pm 4.0$ & 24.7 & 56.5 & $44.2 \pm 6.5$ & 1.0 & 1.8 & $1.19 \pm 0.17$ \\
\hline C. forbesii & 49.4 & 70.6 & $60.0 \pm 4.0$ & 24.7 & 60.0 & $45.9 \pm 7.3$ & 1.0 & 2.0 & $1.34 \pm 0.20$ \\
\hline Dracaena afromontana & 38.8 & 54.3 & $47.6 \pm 4.9$ & 28.6 & 45.7 & $40.0 \pm 5.1$ & 0.7 & 1.7 & $1.21 \pm 0.21$ \\
\hline D. aletriformis & 56.5 & 74.1 & $64.4 \pm 4.6$ & 38.8 & 67.1 & $57.0 \pm 6.2$ & 1.0 & 1.6 & $1.14 \pm 0.15$ \\
\hline D. americana & 24.7 & 35.3 & $30.4 \pm 3.0$ & 17.6 & 31.7 & $22.9 \pm 4.3$ & 1.0 & 1.8 & $1.36 \pm 0.23$ \\
\hline D. arborea & 52.9 & 70.6 & $62.7 \pm 5.5$ & 35.3 & 63.5 & $48.6 \pm 7.7$ & 1.0 & 1.7 & $1.32 \pm 0.21$ \\
\hline D. aubryana & 56.5 & 70.6 & $64.3 \pm 3.0$ & 42.4 & 63.5 & $53.8 \pm 7.3$ & 1.0 & 1.6 & $1.22 \pm 0.20$ \\
\hline D. cambodiana & 28.2 & 42.4 & $36.4 \pm 3.0$ & 21.2 & 35.3 & $27.3 \pm 4.1$ & 1.0 & 2.0 & $1.40 \pm 0.26$ \\
\hline D. camerooniana & 52.9 & 77.6 & $65.5 \pm 6.4$ & 38.8 & 70.6 & $55.9 \pm 6.8$ & 1.0 & 1.6 & $1.18 \pm 0.15$ \\
\hline D. conferta & 42.4 & 67.1 & $56.6 \pm 6.3$ & 28.2 & 56.5 & $40.5 \pm 7.2$ & 1.1 & 2.0 & $1.42 \pm 0.22$ \\
\hline D. deremensis & 49.4 & 67.0 & $57.5 \pm 4.6$ & 28.2 & 56.5 & $46.7 \pm 6.8$ & 1.0 & 1.7 & $1.25 \pm 0.19$ \\
\hline D. draco & 35.3 & 45.8 & $39.8 \pm 3.3$ & 21.2 & 35.3 & $28.2 \pm 3.4$ & 1.1 & 1.8 & $1.43 \pm 0.23$ \\
\hline D. ellenbeckiana & 38.8 & 49.4 & $45.0 \pm 2.9$ & 24.7 & 42.4 & $34.5 \pm 4.6$ & 1.0 & 1.7 & $1.33 \pm 0.17$ \\
\hline D. fragrans & 28.2 & 60.0 & $50.1 \pm 7.0$ & 21.2 & 49.4 & $38.1 \pm 7.4$ & 1.0 & 2.5 & $1.36 \pm 0.31$ \\
\hline D. mannii & 56.5 & 81.2 & $66.9 \pm 5.9$ & 35.3 & 67.1 & $51.1 \pm 8.8$ & 1.0 & 1.9 & $1.35 \pm 0.25$ \\
\hline D. multiflora & 38.8 & 77.6 & $61.7 \pm 8.7$ & 28.2 & 67.1 & $47.7 \pm 10.7$ & 1.0 & 2.3 & $1.37 \pm 0.33$ \\
\hline D. ombet & 24.7 & 31.7 & $28.4 \pm 1.9$ & 14.1 & 28.2 & $22.6 \pm 2.8$ & 1.0 & 2.5 & $1.28 \pm 0.25$ \\
\hline D. pendula & 56.4 & 81.2 & $74.6 \pm 5.2$ & 38.8 & 81.2 & $62.0 \pm 11.2$ & 1.0 & 1.9 & $1.24 \pm 0.25$ \\
\hline D. reflexa & 38.8 & 60.0 & $51.5 \pm 4.8$ & 28.2 & 52.9 & $43.5 \pm 6.1$ & 1.1 & 1.5 & $1.20 \pm 0.12$ \\
\hline D. schizantha & 24.7 & 31.7 & $28.0 \pm 2.5$ & 14.1 & 24.7 & $21.0 \pm 2.9$ & 1.0 & 2.0 & $1.35 \pm 0.22$ \\
\hline D. serrulata & 28.2 & 42.4 & $34.9 \pm 3.5$ & 17.6 & 31.7 & $27.3 \pm 3.8$ & 1.0 & 1.6 & $1.30 \pm 0.17$ \\
\hline D. surculosa var.surculosa & 38.8 & 56.5 & $49.8 \pm 4.1$ & 31.7 & 52.9 & $40.2 \pm 5.6$ & 1.0 & 1.5 & $1.26 \pm 0.17$ \\
\hline ANOVA & \multicolumn{3}{|c|}{$\mathrm{F}=975317.0 P<0.05$} & \multicolumn{3}{|c|}{$\mathrm{F}=271524.4 P<0.05$} & \multicolumn{3}{|c|}{$\mathrm{F}=1361.4 P<0.05$} \\
\hline
\end{tabular}

regarded as systematically significant in monocotyledons above and below the family level (Zavada 1983; Linder and Ferguson 1985; Furness and Rudall 2001). Palynology has been little studied for Dracaena, but it is of considerable importance in systematic studies generally. There are only few works concerning pollen morphology of Dracaena (Erdtman 1952, 1960; Meier and Yaroshevskaya 1973; Ojeda et al. 1984; Guang-Zheng 1993; Ojeda and LudlowWiechers 1995; Bos 1998; Rudall et al. 2000; Mwachala 2005; Patil and Pai 2011). There is also one publication describing pollen of two extinct Dracaena species from the Neogene (Van Campo and Sivak 1976). The pollen of the closely related Sansevieria was also studied by several authors (Ojeda et al. 1984; Ojeda and Ludlow-Wiechers 1995; Buchner and Halbritter 2010; Klimko et al. 2017). To date, no reports have been published concerning pollen of the genus Chrysodracon.

The hypothesis in the present study is that pollen grains of the dracenoid clade species exhibit a greater variation than it has been reported in literature. The main goal of this study was: 1) to describe variation in pollen grain morphology of the 3 species of Chrysodracon and 20 species of Dracaena and 2) to illustrate the microstructure of the pollen grains with the aim of providing new diagnostic features for their characterization and to determine their characters of systematic importance.

\section{Materials and methods}

Pollen was obtained from herbarium specimens deposited at the Royal Botanic Gardens, Kew (K). The samples represent 20 species of Dracaena, including 8 species from the dragon tree group. Moreover, 3 species of Chrysodracon were examined. The scanning electron microscope (SEM) observations were made on pollen grains which were dried, while for light microscope (LM), the pollen grains were macerated with 10\% KOH (Dyakowska 1959; Frederiksen 1978). A sample consisted of 30 mature pollen grains. In total, 750 pollen grains were examined. The pollen terminology was adopted from Faegri and Iversen (1989) and Hesse et al. (2007). The shape classification followed that 
Table 2 Qualitative features of pollen grains in Chrysodracon and Dracaena species

\begin{tabular}{|c|c|c|c|c|c|}
\hline Features species & Size class & $\begin{array}{l}\text { Basic shape based on } \\
\text { mean LA/SA ratio }\end{array}$ & Aperture shape & $\begin{array}{l}\text { Exine ornamentation of } \\
\text { non-apertural areas (proximal } \\
\text { surface) }\end{array}$ & $\begin{array}{l}\text { Exine ornamentation of aper- } \\
\text { tural areas (distal surface) }\end{array}$ \\
\hline Chrysodracon aurea & medium, large & prolate & ulcerate & psilate-perforate & granulate \\
\hline C. fernaldii & medium, large & subprolate & ulcerate & $\begin{array}{l}\text { psilate-perforate, irregularly } \\
\text { folded }\end{array}$ & psilate-perforate \\
\hline C. forbesii & medium, large & prolate & ulcerate & fossulate & $\begin{array}{l}\text { microreticulate, psilate- } \\
\text { perforate }\end{array}$ \\
\hline Dracaena afromontana & medium, large & subprolate & sulcate/ulcerate & fossulate & psilate-perforate \\
\hline D. aletriformis & large & subprolate & sulcate & $\begin{array}{l}\text { psilate-perforate, irregularly } \\
\text { folded }\end{array}$ & microreticulate \\
\hline D. americana & medium, large & prolate & sulcate & fossulate & irregularly folded \\
\hline D. arborea & large & subprolate & sulcate/ulcerate & psilate-perforate & psilate-perforate \\
\hline D. aubryana & large & subprolate & sulcate/ulcerate & psilate-perforate & microreticulate-baculate \\
\hline D. cambodiana & medium, large & prolate & sulcate/ulcerate & psilate-perforate, folded & psilate-perforate \\
\hline D. camerooniana & large & subprolate & sulcate & psilate-perforate & psilate-perforate-verrucate \\
\hline D. conferta & medium, large & prolate & sulcate & psilate-perforate & psilate-perforate-verrucate \\
\hline D. deremensis & medium, large & subprolate & sulcate & microreticulate & psilate-perforate \\
\hline D. draco & medium, large & prolate & sulcate & microreticulate & psilate-perforate \\
\hline D. ellenbeckiana & medium, large & subprolate & sulcate & psilate-perforate, folded & psilate-perforate \\
\hline D. fragrans & medium, large & prolate & sulcate & fossulate & microreticulate, baculate \\
\hline D. mannii & large & prolate & sulcate/ulcerate & psilate-perforate, fossulate & psilate-perforate \\
\hline D. multiflora & medium, large & subprolate & sulcate & fossulate & irregularly folded \\
\hline D. ombet & medium, large & subprolate & sulcate & microreticulate & psilate-perforate \\
\hline D. pendula & large & subprolate & sulcate & psilate-perforate & microreticulate \\
\hline D. reflexa & medium, large & subprolate & sulcate & psilate-perforate, fossulate & microreticulate \\
\hline D. schizantha & medium, large & prolate & sulcate & microreticulate & psilate-perforate \\
\hline D. serrulata & medium, large & subprolate & sulcate & microreticulate & psilate-perforate-verrucate \\
\hline D. surculosa var.surculosa & medium, large & subprolate & sulcate/ulcerate & psilate-perforate, folded & psilate-perforate-verrucate \\
\hline
\end{tabular}

of Erdtman (1952). The size classification followed that of Dyakowska (1959). Pollen grains were analyzed for three quantitative traits, i.e., length of the long axis (LA), length of the short axis (SA) and the LA/SA ratio as well as the following qualitative traits: pollen outline and shape and exine ornamentation on the proximal and distal sides.

\section{Light, scanning electron and fluorescence microscopy}

The observations were carried out under an Olympus BX 43 light microscope equipped with a camera lucida. The SEM micrographs were taken using a Zeiss EVO 40 microscope (Carl Zeiss, Jena, Germany) at an accelerating voltage of $10-15 \mathrm{kV}$, at the Electron and Confocal Microscopy Laboratory, Faculty of Biology, Adam Mickiewicz University in Poznań. Prior to the observations, the prepared material was sputtered with gold using an SCB 050 ion sputter. The study was documented with photographs taken during observations, primarily at magnifications ranging from $\times 2.500$ to $\times 3.500$ for shape and $\times 10.000-20.000$ for exine sculpture of the pollen grains. The observations were carried out in an Olympus BX 43 light microscope equipped with a camera lucida. The pollen from dehiscent anthers was fixed in a mixture of glycerol and ethanol $(1: 1 ; \mathrm{v} / \mathrm{v})$ and then dehydrated stepwise with a graded ethanol series and finally embedded in Epon (Meek 1976). Next, embedded samples were cut with a Tesla 490A microtome into thin ( $3 \mu \mathrm{m})$ sections and glued to the slides with Haupt adhesive ( $1 \%$ gelatin in water with $2 \%$ phenol crystals and $15 \%$ glycerin). Unstained sections were examined under a Zeiss Lab. A1 fluorescence microscope (FM) in UV light (wavelength $365 \mathrm{~nm}$ ) for exine structure analyses.

\section{Statistical analysis}

The minimal and maximal values as well as arithmetical means and standard deviations were calculated for 

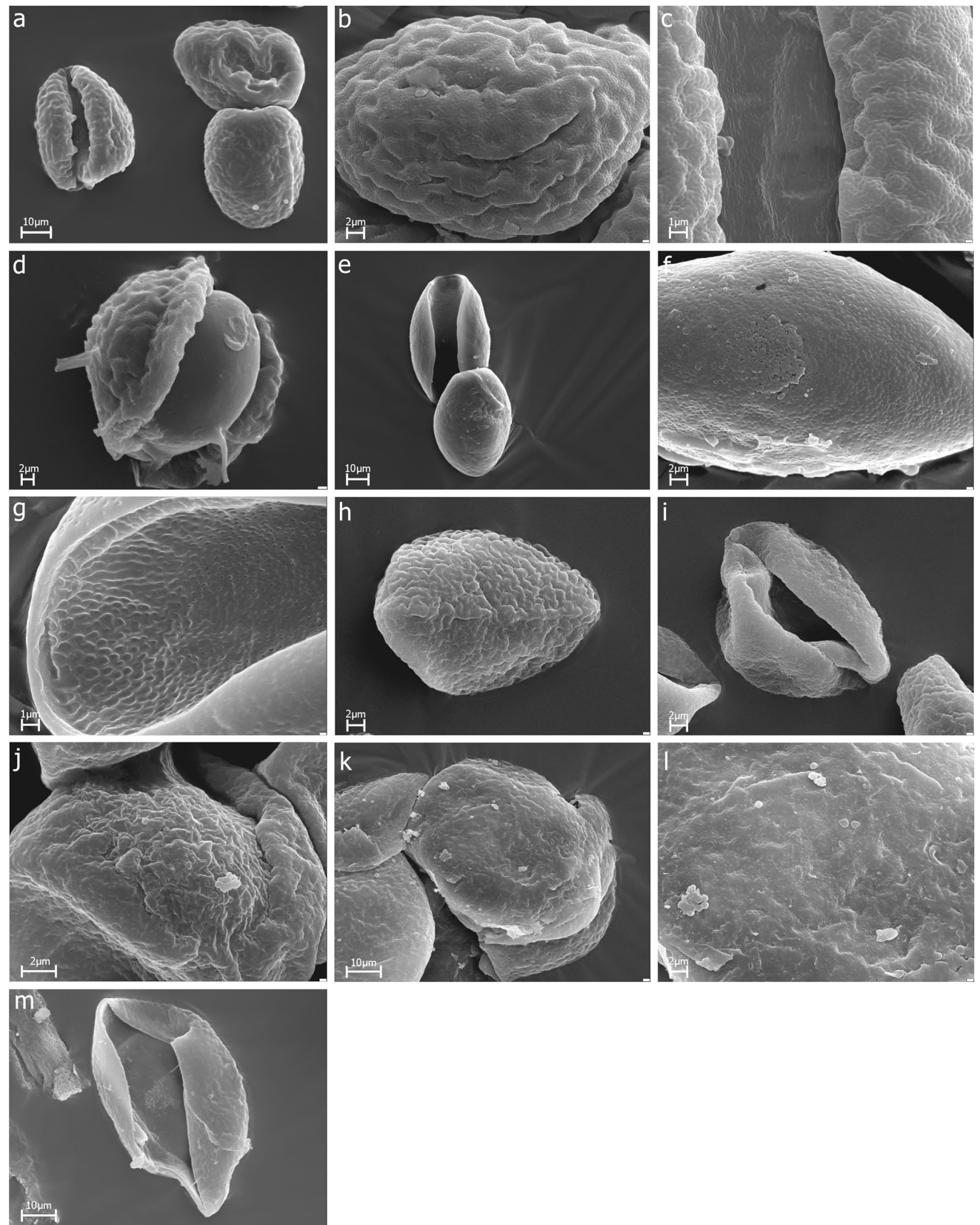

Fig. 2 SEM micrographs of pollen grains of Dracaena species studied. a-d Dracaena afromontana. a In proximal and distal view. b Exine surface of proximal surface. c Distal surface. d Laterally germinating pollen. e-g Dracaena aletriformis. e In proximal and distal view. $\mathbf{f}$ Exine surface, enlargement of $\mathbf{e}$. $\mathbf{g}$ Exine surface, enlargement of $\mathbf{e}$. h-j Dracaena americana. $\mathbf{h}$ In proximal view. $\mathbf{i}$ In distal view. $\mathbf{j}$ Distal surface. $\mathbf{k}-\mathbf{m}$ Dracaena arborea. $\mathbf{k}$ In proximal view. I Exine surface, enlargement of $\mathbf{k}$. $\mathbf{m}$ In distal view 

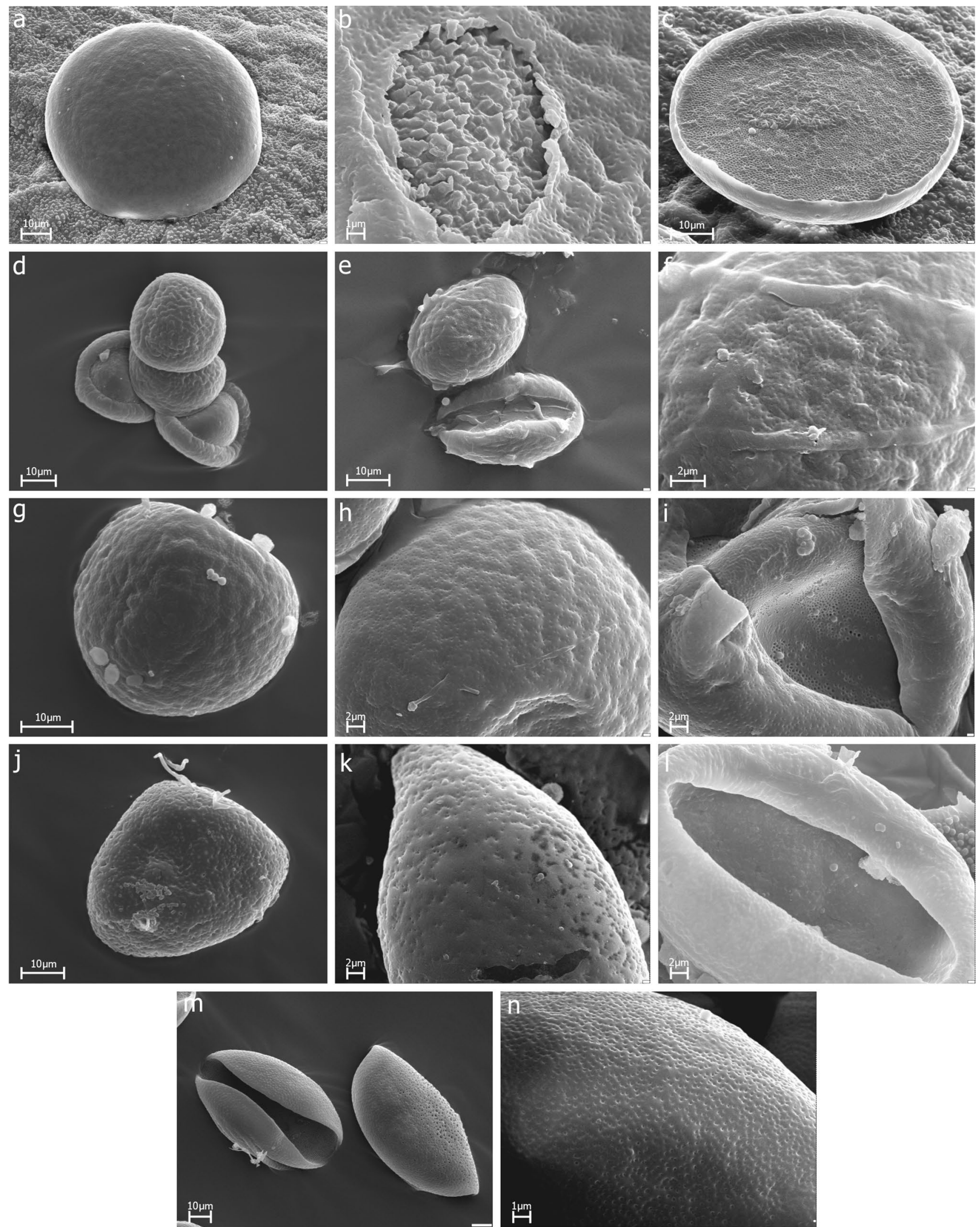

Fig. 3 SEM micrographs of pollen grains of Dracaena species studied. a-c Dracaena aubrayna. a In proximal view. b, c Distal surface. d-f Dracaena cambodiana. d, e In proximal and distal view. f Exine surface, enlargement of e. g-i Dracaena camerooniana. $\mathbf{g}$ In proximal view. $\mathbf{h}$ Exine surface, enlargement of $\mathbf{g}$. $\mathbf{i}$ In distal view. $\mathbf{j}-\mathbf{l}$ Dracaena conferta. $\mathbf{j}$ In proximal view. k Proximal surface. $\mathbf{l}$ In distal view. $\mathbf{m}, \mathbf{n}$ Dracaena deremensis. $\mathbf{m}$ In proximal and distal view. $\mathbf{n}$ Exine surface, enlargement of $\mathbf{m}$ 
quantitative characteristics. Prior to the statistical analyses, the normality and homogeneity of variance for each morphological feature was checked using Shapiro-Wilk's test and Levene's test. Because some of the data did not meet the necessary assumptions, all the data were logarithmically transformed. The one-way ANOVAs and Tukey's HSD tests was used to examine differences in the mean values among the characters of studied species. In ANOVA, the homoscedasticity was checked based on scatter plots between the predictors and the residuals. Statistical analyses were performed using Statistica 12.5 for Windows software.

Specimens investigated included: Chrysodracon aurea (H.Mann) P.L.Lu \& Morden-Hawaiian Islands, Kauai, Heller 2362 (K); C. fernaldii (H.St.John) P.L.Lu \& Morden-Hawaiian Islands, Kamodu, Cowan 22595 (K); C. forbesii (O.Deg.) P.L.Lu \& Morden-Hawaiian Islands, St. John 20230 (K); Dracaena afromontana Mildbr.-Tanzania, SW Kilimanjaro, Haarer 1169 (K); D. aletriformis (Haw.) Bos-South Africa, Hort. Kew, 11/1866 (K); D. americana Donn.Sm.-Belize, El Cayo District, Gentle 2005 (K); D. arborea K.Koch-Equatorial Guinea, Bioco, Malaba, Carvalho 2083 (K); D. aubryana Brongn. ex É.Morren-Cameroon, $17 \mathrm{~km} \mathrm{NE}$ of Deng Deng, Breteler 994 (K); D. cambodiana Pierre ex Gagnep.-Thailand, Baw Re Kanburi, Put 205 (K); D. camerooniana Baker-Congo Republic, Haut-Katanga, Keyberg (Kisanga) near Elisabethville, Symoens 12354 (K); D. conferta Ridl.-Malaysia, Borneo, Sepilok Forest Reserve, Kadir A2744 (K),; D. deremensis Engl.Tanzania, East Usambara Mountains, Borhidi et al. 87237 (K); D. draco L.- Madeira, Mandon 245 (K); D. ellenbeckiana Engl.-Kenya, Northern Province, Sololo, Burroli Mt., Glover \& Samuel 3262 (K); D. fragrans (L.) Ker Gawl.-Equatorial Guinea, Fernando Po, Mioka area, Boughey 96 (K); D. mannii Baker-Tanzania, Eastern Province, Kilosa District, Semsei 1006 (K); D. multiflora Warb. ex P.Sarasin \& Sarasin.-Philippines, Mindoro Paluan, Ramos 39508 (K); D. ombet Kotschy \& Peyr.-Sudan, Mt. Erkowit, Schweinfurth 250 (K); Ethiopia, Friss et al. 10741 (K); D. pendula Peyr.-Malaysia, Telok Forest Reserve, Kepong, Kochumenn 94847 (K); D. reflexa Lam.-Tanzania, Tanga District, Greenway 8709 (K); D. schizantha BakerDjibouti, Wadi Dounyar, S of Ali Sabieh, Collenette 8644 (K); D. serrulata Baker-Saudi Arabia, South Hijag, between Abha and the Najran plateau, Collenette 1291 (K); Yemen, south side of Sebel Minmar (Sadah-Sagayn), Wood 624 (K); D. surculosa var. surculosa Lindl.-Nigeria, Benin Province, Okomu Forest Reserve, Brenan et al. 9027 (K).

\section{Results}

\section{Morphological descriptions and interpretations}

\section{Chrysodracon}

Pollen grains of Chrysodracon species are dispersed as monads, rarely as dyads, e.g., in C. fernaldii (Fig. 1c). Pollen grains are medium-sized $(25-50 \mu \mathrm{m})$ and large $(>50 \mu \mathrm{m})$. The mean length of the long axis (LA) ranges from 51.8 in C. fernaldii to $60.2 \mu \mathrm{m}$ in C. aurea, while the length of short axis (SA) ranges from 40.8 in $C$. aurea to $45.9 \mu \mathrm{m}$ in $C$. forbesii. The outline is circular (Fig. 1a, d, g). The mean LA/ SA ratio ranges from 1.19 in C. fernaldii to 1.53 in C. aurea (Table 1). Pollen shapes (based on LA/SA ratio) are subprolate (C. fernaldii) and prolate (C. aurea and $C$. forbesii), (Table 2). Exine ornamentation on the proximal surface is psilate-perforate in C. aurea (Fig. 1a, b), psilate-perforate and irregularly folded in C. fernaldii (Fig. 1d, e) and fossulate in C. forbesii (Fig. 1g, h). The aperture occupies nearly the entire distal hemisphere, and the proximal face is convex and the distal side is flatter (Fig. 1c) or convex (Fig. 1f, i). The monoulcerate pollen grains are bordered by a rim from the proximal hemisphere thin in $C$. aurea (Fig. 1c) and thick in $C$. forbesii (Fig. 1g, i, j). The germinal aperture of the pollen grains of Chrysodracon is variable in shape: circular (Fig. 1c) or oval (Fig. 1f, i). The apertural area in C. aurea is granulate (Fig. 1c), psilate-perforate-verrucate in $C$. fernaldii (Fig. 1f), while in $C$. forbesii, it is microreticulate (Fig. 1g, i), or psilate-perforate (Fig. 1j).

\section{Dracaena}

Pollen grains in species of Dracaena are found as monads, rarely as dyads, e.g., in $D$. mannii. They differ markedly in their dimensions. Pollen grains are medium-sized (25$50 \mu \mathrm{m})$ and large $(>50 \mu \mathrm{m})$. The mean length of the long axis (LA) ranges from $28.0 \mu \mathrm{m}$ in D. schizantha to $74.6 \mu \mathrm{m}$ in D. pendula, while the mean length of the short axis (SA) ranges from $21.0 \mu \mathrm{m}$ in $D$. schizantha to $62.0 \mu \mathrm{m}$ in D. pendula (Table 1). The outline in the equatorial view is elliptic and circular in the polar view. Pollen grains of Dracaena are bilaterally symmetrical. The basic shape of the pollen grains studied is subprolate and prolate (Table 2). In subprolate pollen grains, the mean LA/SA ratio ranged from 1.14 in $D$. aletriformis to 1.33 in D. ellenbeckiana, whereas in prolate pollen grains, the mean LA/SA ratio ranges from 1.35 in $D$. mannii and D. schizantha to 1.43 in D. draco.

The aperture of pollen grains is variable. The pollen grains possess a monosulcate aperture, which can extend 

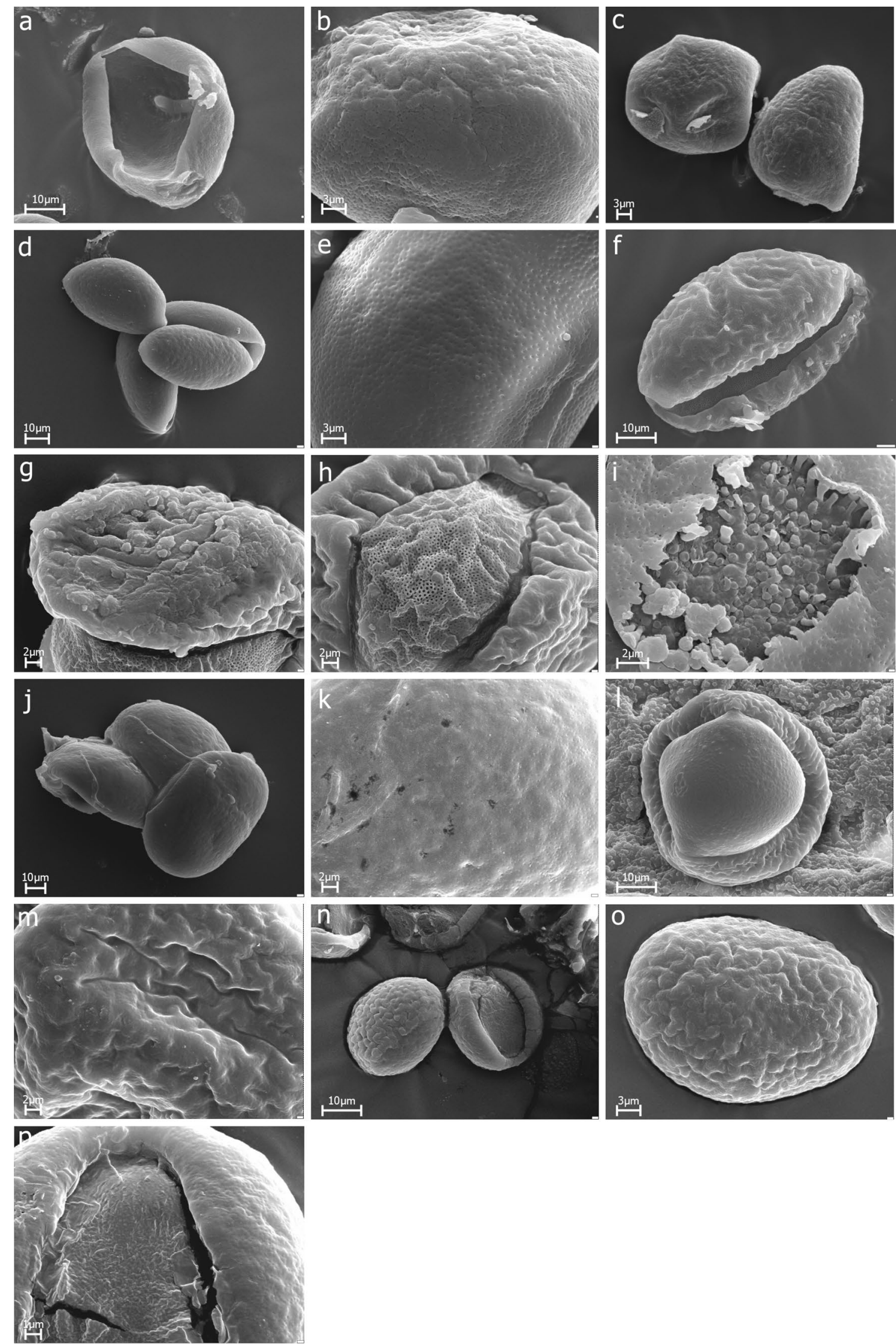
४Fig. 4 SEM micrographs of pollen grains of Dracaena species studied. a-c Dracaena draco. a In distal view. b Proximal surface. c Two pollen grains. d, e Dracaena ellenbeckiana. d In proximal and distal view. e Exine surface, enlargement of $\mathbf{d}$. f-i Dracaena fragrans. $\mathbf{f}$ In lateral view, $\mathbf{g}$ In proximal view. $\mathbf{h}$, $\mathbf{i}$ Distal surface. $\mathbf{j}-\mathbf{m}$ Dracaena mannii. $\mathbf{j}$ In proximal view. $\mathbf{k}$ Exine surface, enlargement of $\mathbf{j} . \mathbf{l}$ In distal view. $\mathbf{m}$ Surface of hemisphere rim. $\mathbf{n}-\mathbf{p}$ Dracaena multiflora. $\mathbf{n}$ In proximal and distal view. o Proximal surface. p Distal surface

from one extremity of the pollen grain to the other (Figs. 2a, e, $3 \mathrm{~m}, 4 \mathrm{~d}, \mathrm{f}, 5 \mathrm{e}, \mathrm{j}$ ) or be shorter (Figs. 2i, m, 3e, 1, 4n, p, 5a, $\mathrm{k}, \mathrm{o})$. Sometimes it is narrow in the middle and wide at the ends (Figs. 2e, 3m, 4d, 5e). The margin of the sulcus in most species is straight (Figs. 2e, m, 3 1, 4a, d, 5e), slightly folded (Figs. 4 p, 5j) or folded (Figs. 2a, j, 3b, 4i).

In D. aubryana (Fig. 3c), D. cambodiana (Fig. 3d), D. mannii (Fig. 41) and in D. afromontana and D. arbo$r e a$, the aperture occupies nearly the entire distal hemisphere (ulcerate pollen). SEM observations (Table 2) showed that ornamentation of non-apertural areas is: microreticulate (Figs. 3m, n, 4b, c, 5b, h, i), fossulate (Figs. 2b, d, h, 4g, h, m, n, o) or psilate-perforate (Figs. 2e, k, 1, 3a, d, g, h, j, k, 4e, j, k, 5c, d, m). The proximal surface in boat-shaped pollen possesses the same sculpturing as the distal surface. However, in $D$. reflexa, the central proximal side has a folded sculpturing (Fig. 5e), while the rest of the surface is psilatefossulate (Fig. 5f). Our study shows that the aperture membranes (Table 2) are microreticulate (Figs. 2g, $4 \mathrm{~g}, \mathrm{~h}, 5 \mathrm{e}, \mathrm{g}$ ), microreticulate-baculate (Fig. 3c), baculate (Fig. 3b, 4i), psilate-perforate (Figs. 2c, m, 3a, m, 4a, f, 1, 5a, j) psilate-perforate-verrucate (Figs. 3i, $51, o, p$ ), and irregularly folded (Figs. $2 \mathrm{j}, 4 \mathrm{p}$ ). Pollen grains in $D$. aubryana and $D$. fragrans have heterogeneous sculpturing on the apertural area (Figs. 3c, 4h, i). Irregular perforations on the proximal and distal surface are present, and the wall structure is tectatecolumellate (Fig. 6).

\section{Chrysodracon versus Dracaena}

The comparison of quantitative features of pollen of Chrysodracon and Dracaena species according to the Tukey's tests $(\mathrm{P}<0.05)$, the studied species formed eleven homogeneous groups for the LA, nine homogeneous groups for the SA characteristic and five groups for LA/SA (Fig. 7). In the case of LA/SA, homogeneous groups were considerably more overlapped as compared to LA and SA. Species of Chrysodracon genus did not form a distinct group in any of studied characteristics. Based on LA and SA, two groups of species from Dracaena genus can be clearly distinguished:
D. schizanta, D. ombet, D. americana and D. serrulata, D. cambodiana, D. draco.

\section{Discussion}

Our study show distinctive variation in pollen grains morphology of the Dracaena and Chrysodracon genera. Pollen grains in most species of both genera are found as monads rarely as dyads. Ojeda et al. (1984) showed dyads and tetrads in D. americana. Pollen grains of Dracaena are large and medium-sized. Among the examined species, the biggest pollen was found in $D$. pendula and the smallest pollen was reported in Dracaena species from the "dragon tree group" (D. afromontana, D. americana, D. cambodiana, D. draco, D. ellenbeckiana, D. ombet, D. schizantha and D. serrulata). In comparison with the study of Ojeda et al. (1984), the recorded dimensions of the pollen grains in $D$. americana and $D$. fragrans are smaller. In the former species, they are $30.4 \times 22.9 \mu \mathrm{m}$ (versus $36.9 \times 23.9 \mu \mathrm{m}$ in the cited work), while in the latter species, it is $50.1 \times 38.1 \mu \mathrm{m}$ (versus $67.8 \times 48 \mu \mathrm{m}$ ). The pollen grain dimensions of $D$. cambodiana were reported to be $28.32 \times 19.68 \mu \mathrm{m}$ (GuangZheng 1993). Based on the findings in this study, they may be bigger, attaining $36.4 \times 27.3 \mu \mathrm{m}$.

Our observations confirmed earlier studies (Erdtman 1952; Ojeda et al. 1984; Ojeda and Ludlow-Wiechers 1995; Bos 1998; Rudall et al. 2000; Mwachala 2005; Patil and Pai 2011) reporting pollen grains in the genus Dracaena as monosulcate. In five species of Dracaena: D. afromontana, D. arborea, D. aubryana, D. cambodiana and D. mannii, pollen is dimorphic, composed of mixed monoulcerate and monosulcate grains. Furness and Rudall (2001) reported that in the order Asparagales, two different types of apertures are present. The appearance of the sulcus in many monocot pollen grains and the shape of the grains itself varies considerably with the respective pollen configuration. The sulcus form types may be important taxonomic characters in some families (Halbritter and Hesse 1993). Monosulcate pollen is considered to be a plesiomorphic feature in monocots and basal angiosperms (Sampson 2000; Furness and Rudall 1999, 2000, 2001). However, some authors express caution when referring to its basal character (Penet et al. 2005). A single aperture at the distal pole characterizes gymnosperm taxa of higher rank, i.e. Cycadopsida, Bennettitopsida and Ginkgopsida (Erdtman 1965; Tekleva et al. 2007; Zavialova et al. 2011; Korszun and Klimko 2014).

The exine microsculpture of the pollen grains of Dracaena and Chrysodracon species provides diagnostic features of systematic importance. Ornamentation is not 

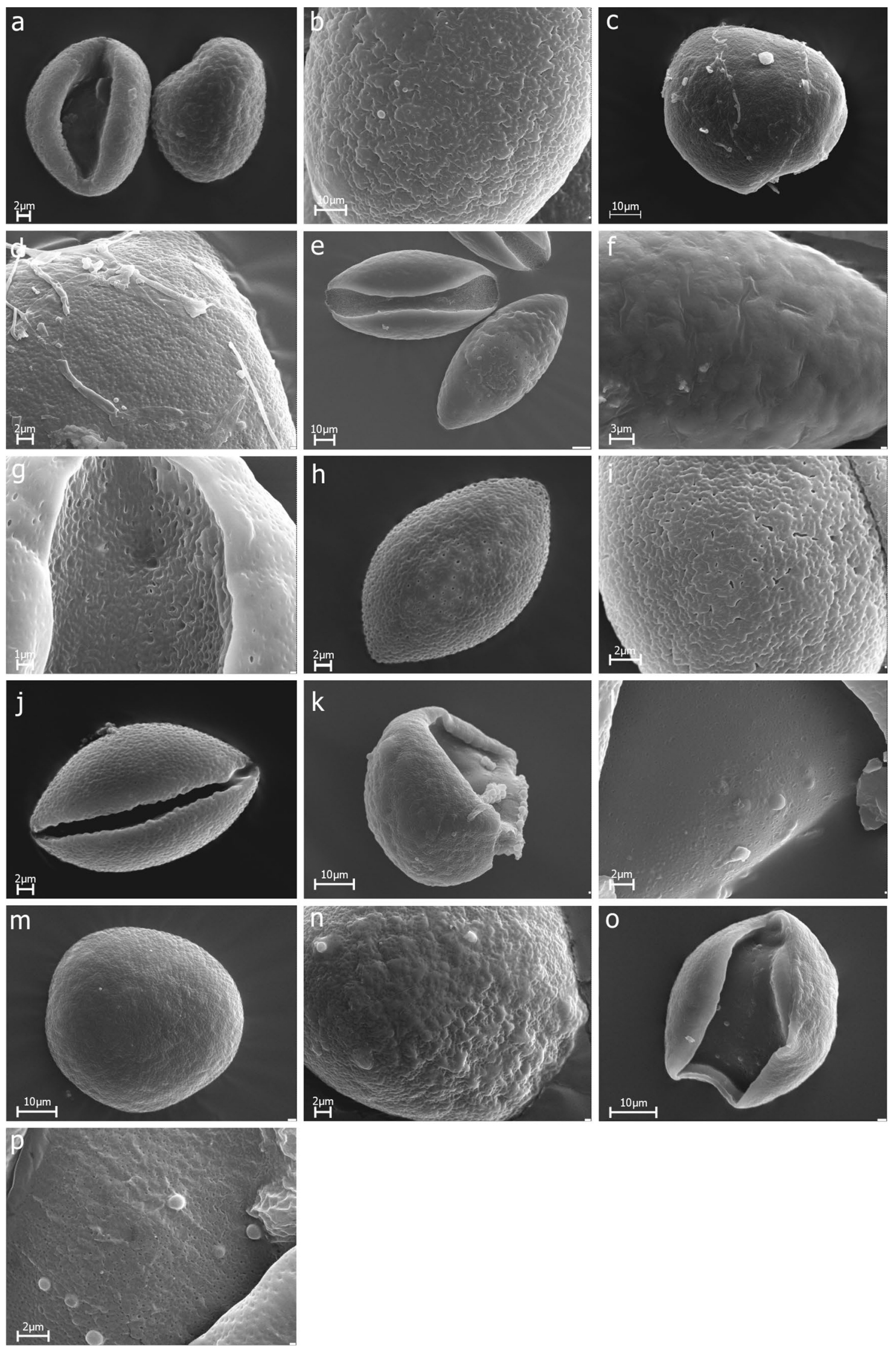
४Fig. 5 SEM micrographs of pollen grains of Dracaena species studied. a, b Dracaena ombet. a In proximal and distal view. b Exine surface, enlargement of a. c, d Dracaena pendula. c In proximal view. d Exine surface, enlargement of c. e-g Dracaena reflexa. e In proximal and distal view. f Proximal surface. g Distal surface. $\mathbf{h}-\mathbf{j}$ Dracaena schizantha. $\mathbf{h}$ In proximal view. $\mathbf{i}$ Exine surface, enlargement of $\mathbf{h}$. $\mathbf{j}$ In distal view. k, $\mathbf{l}$ Dracaena serrulata. $\mathbf{k}$ In lateral view. $\mathbf{l}$ Distal surface. m-p Dracaena surculosa var. surculosa. $\mathbf{m}$ In proximal view. $\mathbf{n}$ Exine surface, enlargement of $\mathbf{m}$. o In distal view. p Exine surface, enlargement of $\mathbf{o}$

uniform all over the pollen grains, but differs between the proximal face and distal pollen regions in studied species. On the proximal surface of the pollen grains, three basic types of the exine sculpturing were distinguished in our study. Also, large differences of the exine sculpture were observed on the apertural area. The exine surface of pollen grains in eight species of Dracaena in China was studied by Guang-Zheng (1993). That author described three types of pollen exine sculpture: foveolate $(D$. cochinchinensis (Lour.) S.C. Chen and D. menglaensis G. Z. Ye), rugulate
(D. cambodiana and D. terniflora Roxb.), reticulate (D. gracilis Wall. ex Baker, D. angustifolia Roxb. and D. ensifolia Wall.) on the proximal side. Ojeda et al. (1984) concluded that the proximal surface of boat-shaped pollen grains in $D$. americana was psilate-perforate, while in $D$. fragrans it was fossulate. In our study, we did not observe in D. cambodiana and D. americana pollen grains like those described above. The sculpturing of the sulcus exine on pollen grains was presented only by Ojeda et al. (1984) in D. fragrans, who described them as microverrucate, while in our study, we observe microreticulate and baculate. The sulcus features and the sulcus membranes are a potential useful systematic character for some of Dracaena examined species. The wall structure was previously examined in Dracaena by Meier and Yaroshevskaya (1973). They concluded that the wall structure was tectate-columellate. Our results are consistent with the descriptions given by those authors. From the palynological point of view, the pollen grains of the examined species of Chrysodracon significantly differ from the most
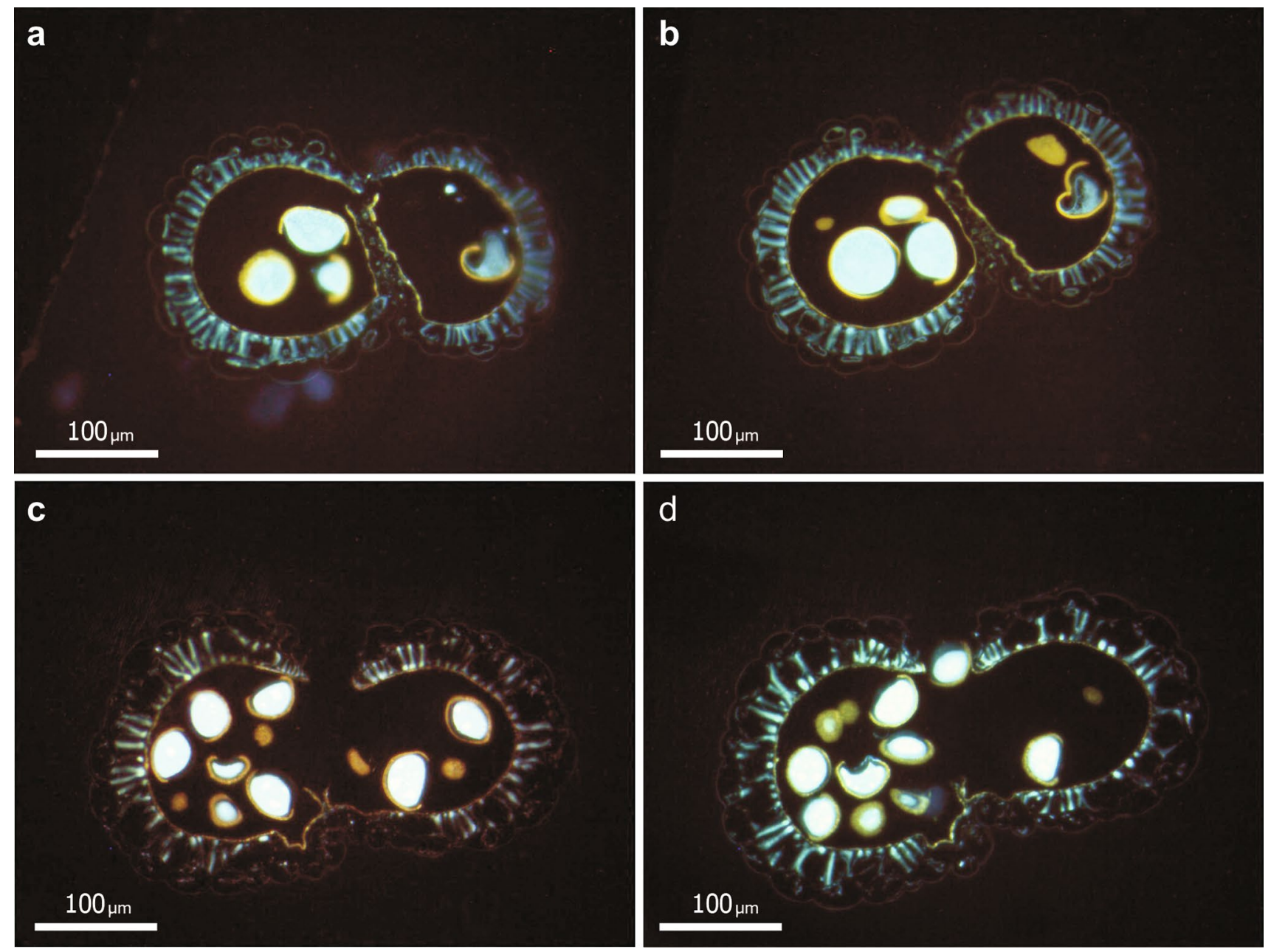

Fig. 6 FM micrographs of exine structure in Dracaena: a, b $D$. aubrayna, c, $\mathbf{d}$ D. reflexa 

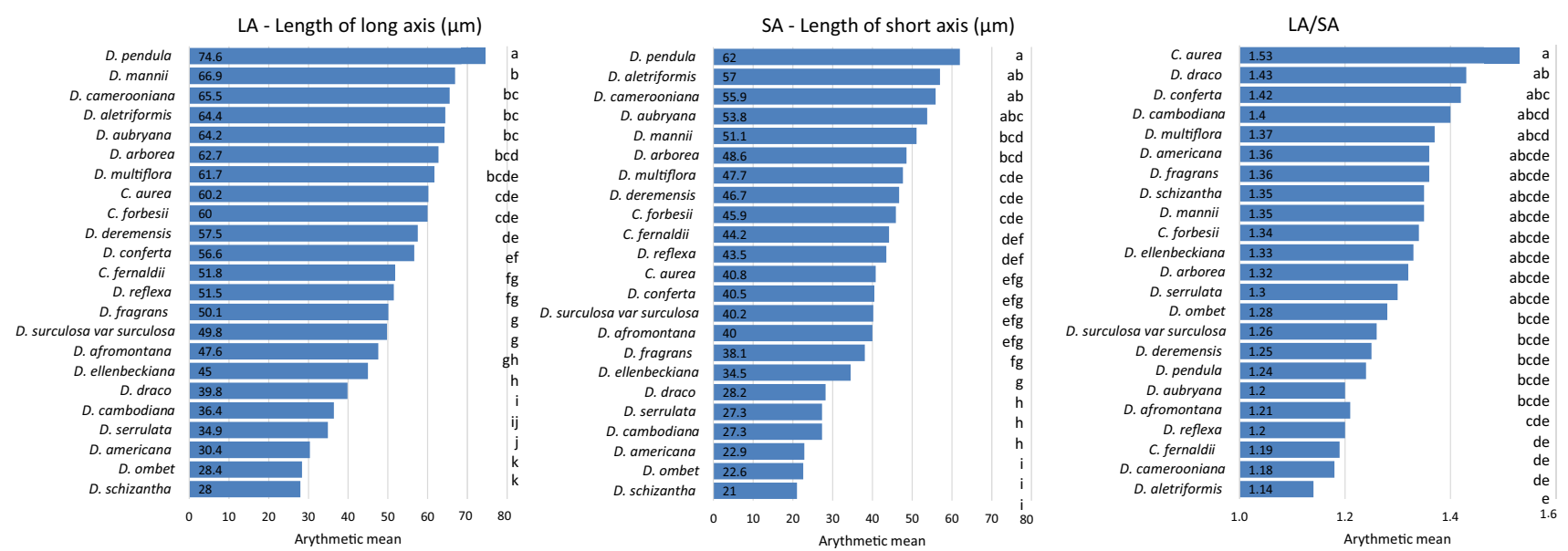

Fig. 7 Arithmetic means and results of Tukey's tests for quantitative characteristics of pollen grains in Chrysodracon and Dracaena. Species denoted by the same letter (s) do not differ significantly at $\mathrm{P}<0.05$

species of Dracaena in apertures type, but are very similar to pollen grains of Sansevieria (Ojeda et al. 1984, Klimko et al. 2017).

\section{Conclusions}

1. The pollen grains from the Chrysodracon and Dracaena genera assessed in terms of their size are classified as medium and large. Their shape is defined as subprolate, prolate or prolate-spheroidal. Based on pollen size and shape, it is not possible to distinguish these two genera.

2. The pollen grains of Chysodracon are monoulcerate whereas in Dracaena-monosulcate and monoulcerate.

3. Exine ornamentation is not uniform all over the pollen grain but differs between proximal face and distal region.

4. The results of investigations of the exine sculpture in pollen grains can be used in taxonomy of species from Chrysodracon and Dracaena genera.

A more extensive study of pollen morphology for all dracenoid genera will provide a more comprehensive understanding of systematic relations between their species.

Acknowledgements We would like to express our gratitude to Ilona Wysakowska for her technical assistance and to Wojciech Klimko for his assistance with computer data records. The authors would like to thank two anonymous reviewers for their suggestions and comments made on an earlier version of the manuscript. This work was carried out with the financial support from the National Science Center (Grant No. N N303 807540), and the Department of Botany, the Poznań University of Life Sciences and the Faculty of Biology, Adam Mickiewicz University in Poznań.

\section{Compliance with ethical standards}

Conflict of interest The authors declare that they have no conflict of interest.

Open Access This article is distributed under the terms of the Creative Commons Attribution 4.0 International License (http://creativecomm ons.org/licenses/by/4.0/), which permits unrestricted use, distribution, and reproduction in any medium, provided you give appropriate credit to the original author(s) and the source, provide a link to the Creative Commons license, and indicate if changes were made.

\section{References}

Apg III (2009) An update of the angiosperm phylogeny group classification for the orders and families of flowering plants; APG III. Bot J Linn Soc 161:105-121. https://doi.org/10.1111/j.1095 $-8339.2009 .00996 . x$

Bos JJ (1984) Dracaena in West Africa. Agricultural University Wageningen, Wageningen

Bos JJ (1998) Dracaenaceae. In: Kubitzki K (ed.) The families and genera of flowering plants, monocotyledons, lilianae (Except Orchidacea). Springer, Berlin, pp 238-241. https://doi.org/10.1007 1978-3-662-03533-7

Brown NE (1914) Notes on the genera Cordyline, Dracaena, Pleomele, Sansevieria, and Taetsia. Bull Misc Inform Kew 8:273-279

Buchner R, Halbritter H (2010) Sansevieria suffruticosa. PalDat-a palynological database. Available at: https://www.paldat.org/pub/ Sansevieria_suffruticosa/100987, Accessed 29.11.2017

Dyakowska J (1959) Podrecznik palynologii, metody, problemy. Wydawnictwa Geologiczne, Warszawa

Erdtman G (1952) Pollen morphology and plant taxonomy. Almqvist and Wiksell, Stockholm

Erdtman G (1960) Notes on finer structure of some pollen grains. Bot Not 113:285-288 
Erdtman G (1965) Pollen and spore morphology and plant taxonomy, vol 2. Gymnospermae, Pteridophyta, Bryophyta. Almqvist \& Wiksell, Stockholm

Faegri K, Iversen J (1989) Textbook of pollen analysis. Wiley, Chichester

Frederiksen NO (1978) Preservation of cycad and Ginkgo pollen. Rev Palaeobot Palynol 25:163-179

Furness CA, Rudall P (1999) Inaperturate pollen in monocotyledons. Int J Pl Sci 160:395-414. https://doi.org/10.1086/314129

Furness CA, Rudall PJ (2000) Aperture absence in pollen of monocotyledons. In: Harley MM, Morton CM, Blackmore S (eds) Pollen and spores: morphology and biology. Royal Botanic Gardens, Kew, London, pp 249-257

Furness CA, Rudall PJ (2001) Pollen and anther characters in monocot systematics. Grana 40:17-25. https://doi.org/10.1080/00173130 152591840

Guang-Zheng YE (1993) Study in the pollen morphology of the genus Dracaena (Liliaceae) in China. Acta Bot Yunnan 15:275-277

Halbritter H, Hesse M (1993) Sulcus morphology in some monocot families. Grana 32:87-99

Hesse M, Halbritter H, Zetter R, Weber M, Buchner R, Frosch-Radivo A (2007) Pollen Terminology. An illustrated handbook, Springer

Jankalski S (2003) Sansevieria versus Dracaena. Sansevieria 8:17-18

Jankalski S (2008) Subgenera and new combination in Dracaena. Sansevieria 18:17-21

Klimko M, Nowińska R, Wilkin P, Wiland-Szymańska J (2017) Pollen morphology of some species of the genus Sansevieria Petagna (Asparagaceae). Acta Biol Cracov, Bot. 59: 63-75. https://doi. org/10.1515/abcsb-2017-007

Korszun S, Klimko M (2014) Microsporangia and pollen morphology of Ginkgo biloba cultivars. Dendrobiology 71:83-92. https://doi. org/10.12657/denbio.071.008

Linder HP, Ferguson IK (1985) Notes on the pollen morphology and phylogeny of the Restionales and Poales. Grana 24:65-76. https:// doi.org/10.1080/00173138509429917

Lu PL, Morden CW (2014) Phylogenetic relationships among Dracenoid genera (Asparagaceae: Nolinoideae) inferred from chloroplast DNA loci. Syst Bot 39:90-104. https://doi.org/10.1600 /036364414X678035

Mansfeld PA (2015) Die Systematik der Gattung Sansevieria (Asparagaceae)-ein aktueller Stand. Sansevieria Online 3:20-29

Meek GA (1976) Practical electron microscopy for biologists. John Wiley and Sons, London
Meier NR, Yaroshevskaya AS (1973) Electron-microscopic study of the wall development of pollen grains in Angiosperms. In: Kupriyanova LA (ed) Methodical problems of palynology. Nauka, Moscow, pp 67-70

Mwachala G (2005) Systematics and ecology of Dracaena L. (Ruscaceae) in Central, East and Southern Africa. PhD Thesis, University of Koblenz and Landau, Koblenz, Landau

Ojeda L, Ludlow-Wiechers B (1995) Palinologia de Agavaceae, una contribución biosistemática. Bol Soc Bot Méx 56:25-43

Ojeda L, Ludlow-Wiechers B, Orellana R (1984) Palinologia de la familia agavaceae para la peninsula de yucatan. Biotica 94:379-398

Patil DA, Pai RM (2011) The Agavaceae: taxonomic and phylogenetic appraisal. J Exp Sci 2:20-24

Penet L, Nadot S, Ressayre A, Forchioni A, Dreyer L, Gouyon PH (2005) Multiple developmental pathways leading to a single morph: monosulcate pollen (examples from the Asparagales). Ann Bot (Oxford) 95:331-343. https://doi.org/10.1093/aob/mci030

Rudall PJ, Conran JG, Chase MW (2000) Systematics of Ruscaceae/ Convallariaceae: a combined morphological and molecular investigation. Bot J Linn Soc 134:73-92. https://doi.org/10.1111/j.1095 -8339.2000.tb02346.x

Sampson FB (2000) Pollen diversity in some modern magnoliids. Int J Pl Sci 161:193-210. https://doi.org/10.1086/317573

Tekleva MV, Polevova SV, Zavialova NE (2007) On some peculiarities of sporoderm structure in members of the Cycadales and Ginkgoales. Paleontol J 41:1162-1178

Van Campo E, Sivak J (1976) Présence de pollens de Dracaena dans le Néogène Méditerranéen. Rev Micropaleontol 18:264-268

Wiland-Szymańska J, Klimko M (2005) Differentiation of leaf anatomy of the genera Dracaena L. and Sansevieria Thunb. (Dracaenaceae). In: XVII international botanical congress, Vienna, Austria, Europe, 17-23 July 2005, Abstracts. IBC, Vienna, p 328

Zavada MS (1983) Comparative morphology of monocot pollen and evolutionary trends of apertures and wall structures. Bot Rev 49:331-379. https://doi.org/10.1007/BF02861086

Zavialova N, Markevich V, Bugdaeva E, Polevova S (2011) The ultrastructure of fossil dispersed monosulcate pollen from the Early Cretaceous of Transbaikalia, Russia. Grana 50:182-201. https:// doi.org/10.1080/00173134.2011.611530 